\title{
Can the world's favorite fruit, tomato, provide an effective biosynthetic chassis for high-value metabolites?
}

\author{
Yan $\mathrm{Li}^{1} \cdot$ Hsihua Wang ${ }^{1} \cdot$ Yang Zhang ${ }^{1} \cdot$ Cathie Martin ${ }^{2}$ (I)
}

Received: 22 January 2018 / Accepted: 22 March 2018 / Published online: 28 March 2018

(c) The Author(s) 2018

\begin{abstract}
Tomato has a relatively short growth cycle (fruit ready to pick within 65-85 days from planting) and a relatively high yield (the average for globe tomatoes is 3-9 $\mathrm{kg}$ fruit per plant rising to as much as $40 \mathrm{~kg}$ fruit per plant). Tomatoes also produce large amounts of important primary and secondary metabolites which can serve as intermediates or substrates for producing valuable new compounds. As a model crop, tomato already has a broad range of tools and resources available for biotechnological applications, either increased nutrients for health-promoting biofortified foods or as a production system for high-value compounds. These advantages make tomato an excellent chassis for the production of important metabolites. We summarize recent achievements in metabolic engineering of tomato and suggest new candidate metabolites which could be targets for metabolic engineering. We offer a scheme for how to establish tomato as a chassis for industrial-scale production of high-value metabolites.
\end{abstract}

Keywords Tomato $\cdot$ Metabolic engineering $\cdot$ Specialized metabolites $\cdot$ Chassis $\cdot$ Scale-up production

\section{An important crop}

Economically, tomato (Solanum lycopersicum) is the most important horticultural crop, and its production, by yield, is second only to potato, across the world (Peixoto et al. 2017). The short life cycle (90-120 days) and self-compatibility of tomato facilitate its cultivation as a cash crop for both small as well as large-scale growers. According to their different commercial uses, tomato varieties can be divided into fresh market varieties which are usually produced in greenhouses and processing varieties which are often field-grown, for industrial uses (Zsögön et al. 2017). Besides water and

Communicated by Neal Stewart.

Yang Zhang

yang.zhang@scu.edu.cn

$\bowtie$ Cathie Martin

cathie.martin@jic.ac.uk

1 Key Laboratory of Bio-resource and Eco-environment of Ministry of Education, College of Life Sciences, Sichuan University, Chengdu 610065, Sichuan, People's Republic of China

2 Metabolic Biology Department, The John Innes Centre, Norwich Research Park, Norwich NR4 7UH, UK fertilizers, successful tomato production requires optimised cultivation methods and management, pest control, and appropriate post-harvest storage (Liu et al. 2017a, b). Under optimized conditions, tomato productivity can easily reach 20-50 tons per hectare (Wang and Seymour et al. 2017; Tieman et al. 2017). China and the United States are the two largest tomato-producing countries in the world (http://faost at3.fao.org/browse/Q/QC/E). In the US, in 2016, the total area under tomato cultivation was 364,800 acres and the total yield reached 16 million tons with a value of just over \$2 billion (USDA 2017; Zsögön et al. 2017).

\section{An excellent crop model with substantial infrastructure as well as tools and resources for metabolic engineering}

Tomato is consumed fresh or as a processed product in canned tomatoes, paste, puree, ketchup, juice and pasta sauces. Tomato consumption globally averages $20 \mathrm{~kg}$ per capita per annum, with the USA, China and Italy consuming double these levels, on average (http://www.agribenchm ark.org). Tomato is the only fruit/culinary vegetable to have increased in consumption in the USA over the past 50 years. 
Some metabolic engineering of tomatoes have been focused on its nutritional improvement as a food, and production of tomatoes enriched in nutrients may be the most cost-effective route to consumers for effective nutritional improvement without requiring substantial shifts in diet (Butelli et al. 2008; Scarano et al. 2017).

Alternatively, tomato can be used as an effective production platform for high-value compounds, such as drugs, and for such uses the primary objective is to extract and purify the high-value bioactives produced (Zhang et al. 2015).

Tomato has been an important model plant for biological research. The genome sequence of tomato has been published (Consortium 2012) and its epigenome and extensive resequencing data are available from the Sol Genomics Network (SGN: https://solgenomics.net) (Lin et al. 2014). The Tomato Genomics Resources Database (TGRD: http://59.163.192.91/tomato2/) houses RNA-seq and microarray data for tomato as well as some metabolite data. TGRD allows interactive browsing of tomato genes, micro RNAs, simple sequence repeats (SSRs), quantitative trait loci (QTL) and the Tomato-EXPEN 2000 genetic map (Suresh et al. 2014). There are extensive genetic resources in the form of well characterised mutant collections (Tomato Genetic Resource Center, TGRC University of California, Davis: http://tgrc.ucdavis.edu/), several excellent TILLING populations for mutant discovery (UC Davis in Heinz1706; INRA Bordeaux in MicroTom, INRA Versailles in M82), Red Setter and Money Maker (phenotypes available through SGN and LycoTILL) and a phenotypic library of additional mutations catalogued in 'The Genes that Make Tomato' available through SGN. Recent progress in tomato metabolomics now provides substantial information about its primary and specialized metabolism and the pathways involved in synthesis and turnover (Luo 2015; Tieman et al. 2017; Zhu et al. 2018). Together with efficient genome editing tools (Brooks et al. 2014; Sprink et al. 2015; Soyk et al. 2017), these advantages make tomato an excellent choice for metabolic engineering. The community of scientists working on tomato is also exceptionally collaborative, with researchers exchanging mutants, accessions, genomics data and new protocols freely and constructively, prior to publication.

The conflict between demands for specific metabolite production and growth dependent on photosynthesis places limits on the levels of production of specialized metabolites possible in photosynthetic tissues, but fruit-specific production in tomato allows high productivity without yield penalties (Butelli et al. 2008; Luo et al. 2008; Zhang et al. 2015). The tomato fruit represents an open system into which additional sugars and amino acids can be imported in times of increased metabolic demand (increased sink strength). This means that switching on metabolic pathways in fruit, late in ripening (as conferred by the fruit-specific $E 8$ promoter, for example) can result in high levels of accumulation of metabolites without yield penalties, because fruit set, development and ripening are largely completed by this point (Butelli et al. 2008; Luo et al. 2008; Zhang et al. 2015; Scarano et al. 2017). Because tomato is such a good system for metabolic engineering, many isogenic lines enriched in different polyphenols are available for comparative nutrition experiments. In addition, lines important for metabolic engineering, such as the E8:AtMYB12 line that induces primary metabolism (glycolysis, the TCA cycle, the pentose phosphate and the shikimate pathways) as well as flavonoid biosynthesis specifically in fruit, are already available and well characterised (Luo et al. 2008; Zhang et al. 2015).

Like other models, methods for stable and transient expression/silencing of target genes in tomato are well developed (Potrykus 1991; Fischer 1999; Hannon 2002; Orzaez et al. 2009). Recently, with the emergence of the new breeding technologies of genome editing, new alleles can be created, directly into the desired genetic background, to supply beneficial quantitative variation for tomato breeding (Rodríguez-Leal et al. 2017). CRISPR/Cas9 genome editing appears to be particularly efficient in tomato (Belhaj et al. 2015; Brookes et al. 2014; Pan et al. 2016).

Compared to other model plants, there are several unique research tools that have been developed to facilitate tomato research: a specialized variety, MicroTom, has a shorter growth cycle and reduced plant size. This cherry tomato variety can be used for fundamental research before traits are transferred to large-sized, globe tomato varieties (Dan et al. 2006). Use of the ethylene-inducible $E 8$ promoter ensures the expression of transgenes is induced only in ripe fruit. The $E 8$ promoter can be used in a general strategy to produce desirable compounds in fruit without yield penalties (Bovy et al. 2002; Luo et al. 2008; Zhang et al. 2015). In addition, the establishment of the $S$. lycopersicum $\times$ S. pennellii introgression lines (ILs) [and now, other IL populations including S. lycopersicum $\times$ S. lycopersicoides, S. lycopersicum $\times S$. pimpinellifolium, S. lycopersicum $\times S$. sitiens, S. lycopersicum $\times S$. chilense, and S. lycopersicum $\times S$. habrochaites $(S$. hirsutum)] has provided unique genetic resources to identify loci controlling important traits in tomato (Zamir 1995, 2001; Eshed and Zamir 1995; Frary et al. 2000; Fridman et al. 2000; Kushibiki and Tabata 2005; Powell et al. 2012).

\section{Metabolic engineering}

Metabolic engineering is used to increase the accumulation of target metabolites in organisms. Metabolic engineering can be achieved by breeding of selective genotypes but more usually involves genetic engineering. Recent advances in genome editing are making this technique an additional option for many traits in tomato. 
Most principles of metabolic engineering have been established in microbial systems, even for the production of plant natural products (Liu et al. 2017a, b) although there is increasing interest in using plants as chassis (O'Neill and Kelly 2016), especially for the development of nutritionally enhanced foods. The principles of metabolic engineering of plant natural products in microbes involve ensuring that each enzyme of the pathway is expressed, that each enzyme has optimized activity, that the flux along the pathway is selectively elevated, and that competing and catabolic pathways are blocked (Liu et al. 2017a, b). While these principles also hold true in plant metabolic engineering, the tools available to ensure that these design principles are met, are different in plants to those in heterologous microbial hosts. Originating from attempts to engineer lipid metabolism for the accumulation of oils, the terms 'push', 'pull' and 'protect' have been used to describe different engineering strategies (Van et al. 2014; Vanhercke et al. 2014). 'Pull' involves up-regulating the activities of enzymes that make the target molecule, particularly 'key, rate-limiting' steps in the biosynthetic metabolic pathways. Such approaches have been used very extensively in plant metabolic engineering, and usually provide modest increases in target metabolite content (Martin 1996; Farré et al. 2014). A good example is the enhanced production of flavonols in tomato resulting from ectopic expression of chalcone isomerase (Muir et al. 2001). 'Protect' strategies involve reductions in flux through pathways that compete for substrate or intermediates on route to the target molecule, or removing catabolic pathways that limit the accumulation of the target metabolite. Protect strategies have proved effective in folate biofortification of rice and in provitamin A engineering in sorghum (Blancquaert et al. 2015; Che et al. 2016). 'Push' strategies encompass those that increase flux along the biosynthetic pathways including activating transcription factors (TFs), as well as strategies that increase the supply of precursors from primary metabolism (Martin 1996; Butelli et al. 2008; Century et al. 2008; Luo et al. 2008; Fu et al. 2018). Generally, push strategies involve the use of transcriptional activators in plants that induce specific pathways, but recently a new type of transcriptional activator that can induce pathways of primary metabolism as well as those of secondary metabolism has been added to the toolbox. These TFs increase flux by supplying increased levels of substrates from primary metabolism, as well as energy and reducing power. Examples are: MYB12 (Zhang et al. 2015), WRI1 that activates fatty acid biosynthesis (Maeo et al. 2009; Baud et al. 2010; Marchive et al. 2015) and GAME9 from tomato that upregulates the MEP pathway to supply isopentyl phosphate precursors for terpenoid and sterol biosynthesis (Cárdenas et al. 2016). Although these activities may have been demonstrated originally in other species, all these tools are available for metabolic engineering in tomato (Fu et al. 2018).

\section{Tomato: an excellent biosynthetic chassis}

Tomato is the world's favorite fruit due to its special flavor and high nutritional value. Tomato fruit contains large amounts of metabolites such as sucrose, hexoses, citrate, malate and ascorbic acid. There are also many healthbeneficial compounds such as carotenoids, phenylpropanoids and terpenoids that accumulate in tomato fruit (Fig. 1; Siddiqui et al. 2015). The existence of these compounds establishes that many basic biosynthetic pathways are intact in tomato. Therefore, when undertaking metabolic engineering, a limited number of additional genes needs to be introduced, which can significantly simplify the engineering process. In addition, substrates (such as sugars and aromatic amino acids) and intermediates (such as 4-coumaroyl CoA and acetyl-CoA) that are needed for secondary metabolism are often enriched in tomato fruit (Fig. 1). All these features facilitate the use of tomato fruit as a chassis for metabolic engineering.

So far, the best examples of metabolic engineering in tomato involve the phenylpropanoid pathway. Phenylpropanoids arise from the essential amino acid phenylalanine and $p$-coumaroyl CoA produced from phenylalanine by the general phenylpropanoid pathway (Fig. 1; Vogt 2010). Tomato fruit contain various phenolic compounds (flavonoids, caffeoyl quinic acids and other hydroxycinnamates) which show that the phenylpropanoid biosynthetic network is intact and active in fruit and can be engineered to either enhance the production of existing phenylpropanoids or produce new types of compound. Over-expression of genes encoding purported 'rate-limiting steps' in the phenylpropanoid pathway was first used to induce biosynthesis, particularly of flavonoids (Muir et al. 2001; Vogt 2010; Tzin et al. 2013). Several MYB and bHLH transcription factors (TFs) have been shown to induce the expression of phenylpropanoid biosynthetic genes. Overexpression of these TFs in tomato fruit can significantly enhance the production of phenylpropanoids (Bovy et al. 2002; Broun et al. 2006; Luo et al. 2008; Butelli et al. 2008; Gonzali et al. 2009; Zhang et al. 2015). Introduction of new structural genes encoding enzymes into tomato can create new compounds such as resveratrol and genistin from current biosynthetic pathways (Schijlen et al. 2006; Carrillo et al. 2011; Zhang et al. 2015). Recently, using the Arabidopsis transcription factor AtMYB12, we managed to switch on aromatic amino acid biosynthesis by manipulating primary metabolism. The AtMYB12 protein not only efficiently induces production of phenylpropanoid compounds, but also has the potential to induce the production of highvalue metabolites derived from tyrosine and tryptophan in tomato (Zhang et al. 2015). 


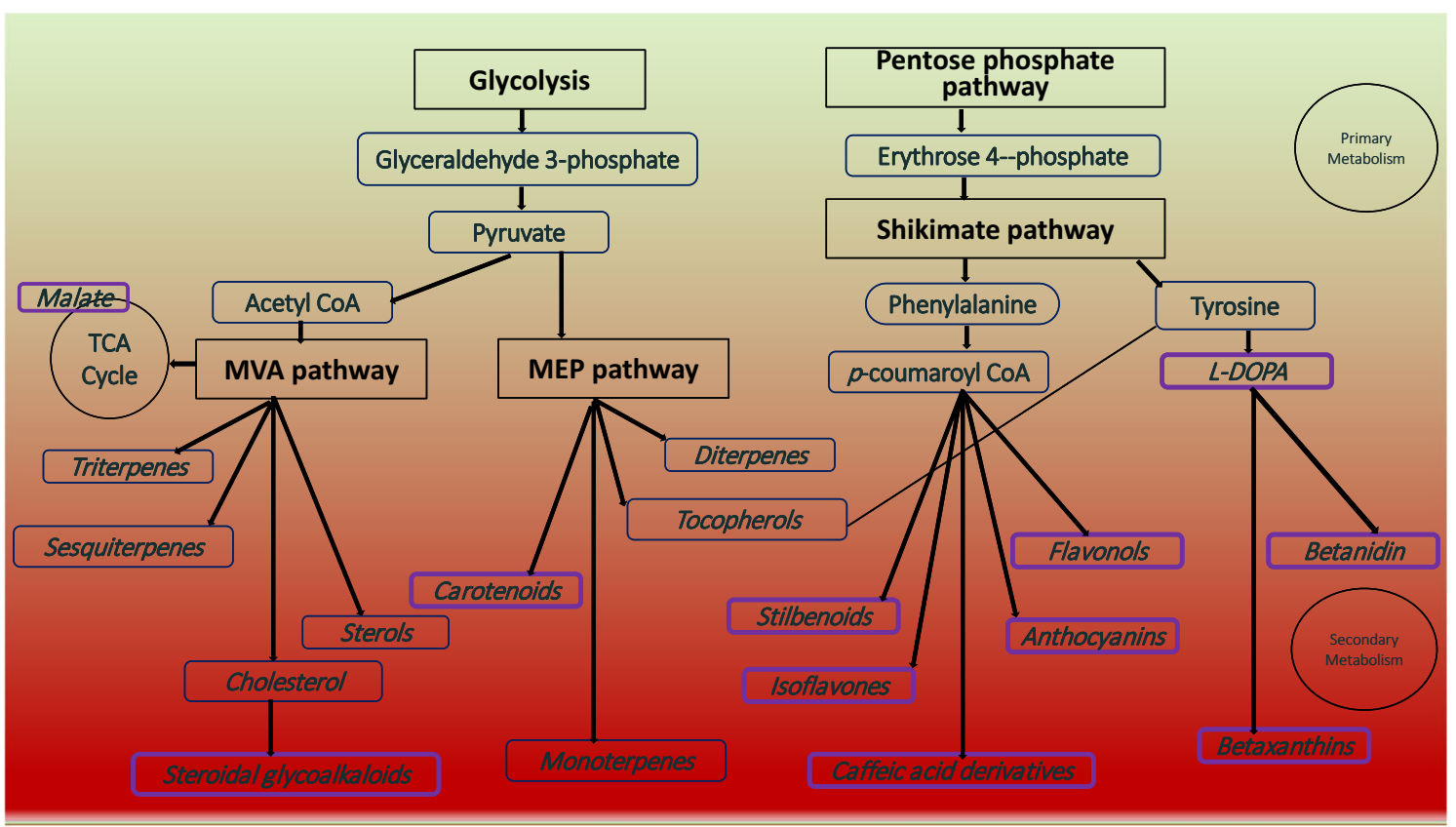

Fig. 1 Important primary and secondary metabolites and their biosynthetic pathways in tomato fruit. Compounds that have been engineered already in tomato fruit are outlined in purple

\section{Examples of high-value metabolites produced in tomatoes}

Betalains, one of the three major types of pigments in plants, provide the colors seen in fruits and flowers of some members of the family Caryophyllaceae. Betalains have been used extensively as natural colorants for many centuries (Georgiev et al. 2008). They are tyrosine-derived, red-violet and yellow pigments used as food colorants and dietary supplements, which are generally classified into the red betacyanins and the yellow betaxanthins (Schwinn et al. 2016). Metabolic engineering for heterologous betalain production was achieved for the first time in tomato, following expression of three genes encoding the cytochrome $\mathrm{P} 450$ CYP76AD1, the BvDODA1 dioxygenase, and the cDOPA5GT glycosyltransferase in a single binary vector. As much as $248 \pm 41 \mathrm{mg} \mathrm{L}^{-1}$ betalain were produced in tomato juice. In addition, these lines have been crossed with a Del/Ros 1 tomato line with elevated anthocyanin production, which can further increase the content of betalain in fruit (Butelli et al. 2008; Polturak et al. 2017).

Recently, tomato fruit have been engineered to produce ketocarotenoids. Ketocarotenoids, such as canthaxanthin, adonirubin, or astaxanthin are high-value pigments used commercially across the food and feed industries, although they are rarely synthesized in plants. This engineering strategy involved both the enrichment and the extension of the $\beta$-carotene pathway. The genes encoding $\beta$-carotene hydroxylase $(\mathrm{Crt} Z)$ and the oxyxgenase $(\mathrm{CrtW})$ from Brevundimonas sp. as well as the allele encoding the lycopene $\beta$-cyclase $(\beta$-Cyc) from Solanum galapagense were introduced into tomato fruit. Two independent aquacultural trials identified that the plant-based feeds developed were increased in the retention of the main ketocarotenoids twofold, in the fillets of fish fed on ketocarotenoid-enriched feed compared to control feed (Nogueira et al. 2017).

\section{New high value compounds can be produced by tomato}

Based on our understanding of the metabolic networks active in tomato fruit and previous metabolic engineering studies, other bioactive compounds that could be produced successfully in tomato can be suggested.

For the biosynthesis of Rosmarinic Acid (RA), there are two precursors, L-phenylalanine (which is converted to $p$-coumaroyl-CoA, catalyzed by the enzymes of the General Phenylpropanoid Pathway, phenylalanine ammonia lyase, cinnamate 4-hydroxylase, and $p$-coumaroyl CoA ligase) and L-tyrosine which is converted to 4-hydroxyphenyllactic acid, catalyzed by tyrosine aminotransferase (TAT) and 4-hydroxyphenylpyruvate reductase (HPPR), enzymes which are active in tomato fruit. The activity of RA synthase produces 4-coumaroyl-4'-hydroxyphenyllactic acid, and then the 3- and 3'-hydroxyl groups are introduced by a cytochrome $\mathrm{P} 450$ monooxygenase to produce $\mathrm{RA}$ ( $\mathrm{Ru}$ et al. 2016). Previous studies have indicated that AtMYB12 can 
enhance significantly the synthesis of aromatic amino acids (phenylalanine, tyrosine and tryptophan) (Zhang et al. 2015). Thus, co-expression of AtMYB12 and additional structural genes could be used to produce substantial amounts of RA in tomato.

Pharmacological studies have shown that retinol (vitamin A) is essential for the development of the human central nervous system (CNS). Retinol can help resist Parkinson's disease and Alzheimer's disease (Kunzler et al. 2017; Liu et al. 2017a, b; Sato et al. 2017). In tomato, enhancing the levels of provitamin A can be achieved by manipulating $\beta$-carotene biosynthesis. $\beta$-carotene concentrations can be improved either by increasing synthesis or reducing catabolism. Lycopene, with high lipophilic antioxidant capacity, is the red compound that accumulates in ripe tomatoes, and lycopene can be metabolized to $\alpha$-carotene or $\beta$-carotene. Therefore, selection of weaker alleles of the gene encoding lycopene $\varepsilon$-cyclase $(L c y E)$, an enzyme that transforms alltrans lycopene into $\delta$-carotene, has been shown to enhance the concentration of $\beta$-carotene. Alternatively, weakening the expression of the gene encoding $\beta$-carotene hydroxylase $(H y d B)$, which converts $\beta$-carotene to zeaxanthin, can increase $\beta$-carotene levels in tomato by a 'protect' strategy. $\beta$-carotene can be converted to two molecules of retinol, meaning that $\beta$-carotene is a better source of provitamin A than other carotenoids which can give rise to only one molecule of retinol. Overexpression of the gene encoding carotene $\varepsilon$-ring hydroxylase (CYP97C), turns $\alpha$-carotene into lutein which is richest in green leafy vegetables (such as spinach, broccoli, peas and lettuce), and protects against the development of age-related macular degeneration (AMD), due to its selective accumulation in the macula of the retina of the eye. $\beta$-carotene improves visual function in patients with age-related cataracts and non-proliferative diabetic retinopathy (Olmedilla et al. 2003; Zhu et al. 2010; Zhang et al. 2017).

There are two forms of vitamin E vitamers (tocopherols and tocotrienols) collectively defined as tocochromanols in most plants. The bioavailability of tocochromanols is dependent on their affinity for the $\alpha$-tocopherol transporter in the liver of humans, and tocochromanols protect against low density lipoprotein (LDL) and polyunsaturated fatty acid (PUFA) oxidation, cardiovascular disease, some cancers and impaired immune function (Martin and Li 2017). Tocotrienols are not produced in tomato because of the absence of a gene encoding homogentisate geranylgeranyl transferase (HGGT) in tomato (Lu et al. 2013). Screening for stronger alleles of the gene encoding homogentisate phytyl transferase (HPT; vte2) could increase significantly the concentrations of tocopherols in tomato (Mène-Saffrané and Pellaud 2017).

Cholesterol and its derivatives are precursors for thousands of important compounds including: the steroidal saponin, diosgenin, which serves as a hormonal drug as well as its derivative progesterone; the steroidal alkaloid (SA) solamargine, which serves as potential cancer drug as well as pro-vitamin D3, which is also known as 7-dehydrocholesterol (Sonawane et al. 2016). SAs and their glycosylated forms (steroidal glycoalkaloids; SGAs) are nitrogen-containing toxic compounds occurring primarily in the Solanaceae and Liliaceae plant families. Although SGAs confer resistance of Solanaceous species to a comprehensive list of pathogens and predators, some are regarded as anti-nutritional compounds for humans including $\alpha$-tomatine and dehydrotomatine in green tissues of fruit (Itkin et al. 2013; Sonawane et al. 2016). The elucidation and manipulation of the cholesterol pathway in tomato could be a first step towards plant-based engineering of interesting cholesterol derivatives. One of the steroidal alkaloids, dioscin, is the main bioactive component of Dioscorea nipponica Makino tubers, and has been used as a marker compound for evaluating the quality of Dioscorea nipponica Makino in traditional Chinese medicines (Yin et al. 2010). Dioscin is an essential feed stock for the steroidal hormone industry, and because it has the same carbon skeleton as SGA, it could be produced in tomato.

\section{Scale-up of production in tomato}

To assemble a successful production platform, a controlled space for cultivation of genetically engineered plants needs to be established, unless field cultivation has been granted regulatory approval. Containment can be accomplished using insect-proofed greenhouses for cultivating tomatoes. The end product of this process could be tomato juice containing the target metabolites. Seeds could be removed during juicing to avoid any potential environmental impact. Plant waste and pumice can be devitalized by autoclaving or incineration (Fig. 2).

A second strategy involves adaptation of any new production system to current industrial processes. A tomato production system could be divided into two major parts: the production of tomato juice and the purification of desired compounds (Fig. 2). The first part could be adapted to current methods used in the juice production industry, where equipment and protocols have already been optimised to remove seeds and concentrate juice. The only difference would be the replacement of non-GM field-grown tomatoes with fruit from engineered plants cultivated in containment greenhouses. For the second stage, tomato juice could be processed further to produce high-purity compounds. This stage could be readily adapted from existing microbial production platform purification protocols. In such cases, tomato juice containing high-value metabolites would replace the microbial medium in purification protocols. All 


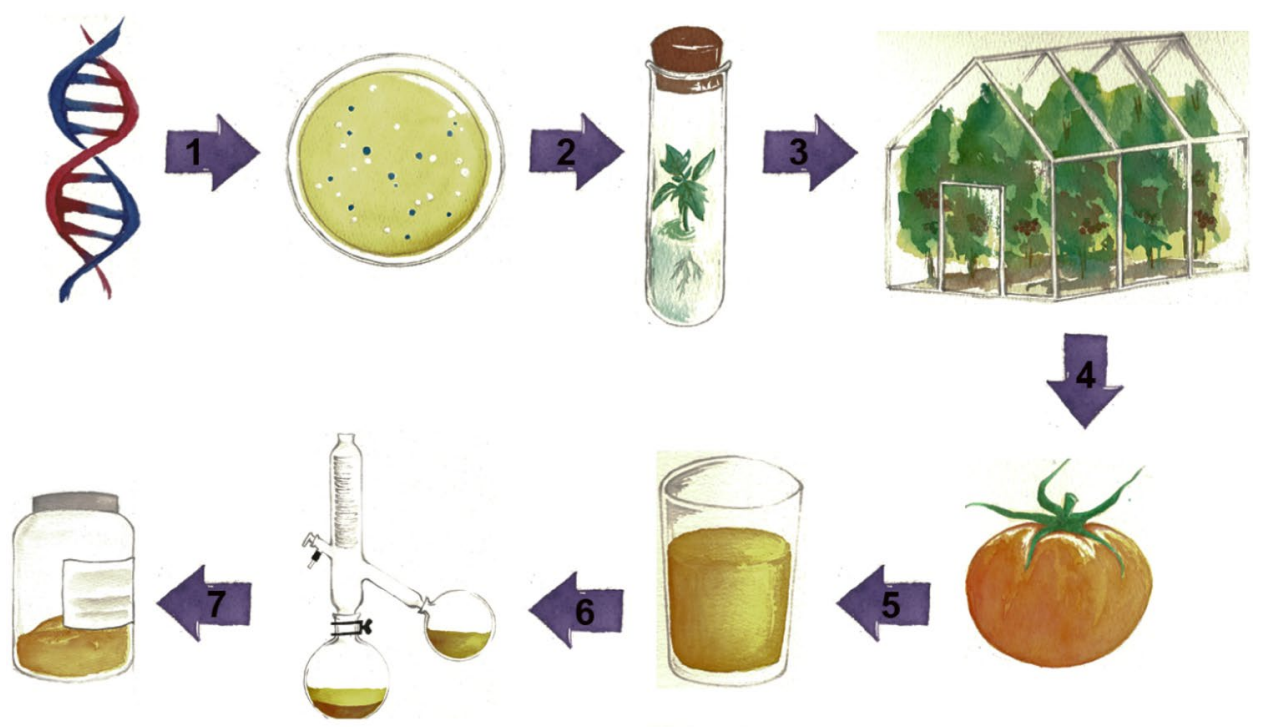

Fig. 2 Production of valuable metabolites using the proposed tomato production platform. Using metabolic engineering, valuable compounds can be produced in tomato fruit. The engineered tomato plants could be grown in containment greenhouses. Fruit juice could be processed to produce metabolite extracts and downstream facilities could be used to purify target compounds. (1) Construction of vectors for metabolic engineering in tomato fruit; (2) agrobacteriummediated transformation of tomato to produce engineered fruit; (3)

techniques used for purification of metabolites from microbial medium should be similarly applicable to tomato juice. To summarize, tomato production platforms could readily be developed based on existing infrastructure for glasshouse cultivation of fresh market tomatoes coupled to existing industrial purification platforms by combining practices from the tomato juice industry with microbial production systems (Fig. 2).

\section{Conclusions}

Tomato offers a useful chassis for metabolic engineering, with significant advantages over other chassis: (a) it is high yielding, easy to grow and manage with existing tomato cultivation infrastructure; (b) fruit contain most of the necessary substrates; (c) fruit contain the whole or most of the biosynthetic pathways for making high-value metabolites and activity can be further enhanced by engineering the activity of transcription factors (Fu et al. 2018); (d) genome sequence is available with many additional tools and resources that facilitate metabolic engineering; (e) fruitspecific production of secondary metabolites usually does not incur a yield penalty nor affect the growth of the plant. Tomato should be considered more frequently for sustainable production of high-value specialty metabolites.

multiplication of engineered lines for cultivation in containment (insect-proofed) greenhouses; (4) harvesting of fruit; (5) preparation of extracts of high value chemicals from tomatoes. This may be as simple as homogenization and centrifugation to generate 'tomato water' for high value, water soluble compounds; (6) chemical separation methods for purification of high value compounds; (7) sale of high value metabolite products from tomato

Author contribution statement $\mathrm{YL}, \mathrm{YZ}$ and $\mathrm{CM}$ conceived and co-wrote this review. HW drew Fig. 2.

Acknowledgements Y.L. and Y.Z. were funded by a Grant from the National Natural Science Foundation of China (31701255). Y.Z. was also supported by the National One Thousand Young Talents program from China and the Fundamental Research Funds for the Central Universities (YJ201640 and 2017SCU04A11). C.M. was supported by the Institute Strategic Program "Understanding and Exploiting Plant and Microbial Secondary Metabolism" (BB/J004596/1) from the BBSRC, the ERA-CAPS project RegulaTomE funded by the BBSRC (BB/ N005023/1), CAS/JIC, and the Center of Excellence for Plant and Microbial Sciences (CEPAMS) joint foundation.

\section{Compliance with ethical standards}

Conflict of interest The authors declare that they have no conflicts of interest.

Open Access This article is distributed under the terms of the Creative Commons Attribution 4.0 International License (http://creativeco mmons.org/licenses/by/4.0/), which permits unrestricted use, distribution, and reproduction in any medium, provided you give appropriate credit to the original author(s) and the source, provide a link to the Creative Commons license, and indicate if changes were made. 


\section{References}

Baud S, Bourrellier ABF, Azzopardi M, Berger A, Dechorgnat J, Danielvedele F, Lepiniec L, Miquel M, Rochat C, Hodges M (2010) PII is induced by WRINKLED1 and fine-tunes fatty acid composition in seeds of Arabidopsis thaliana. Plant J Cell Mol Biol 64:291-303

Belhaj K, Chaparro-Garcia A, Kamoun S, Patron NJ, Nekrasov V (2015) Editing plant genomes with CRISPR/Cas9. Curr Opin Biotechnol 32:76-84

Blancquaert D, Van DJ, Strobbe S, Kiekens F, Storozhenko S, De SH, Gellynck X, Lambert W, Stove C, Van DSD (2015) Improving folate (vitamin B9) stability in biofortified rice through metabolic engineering. Nat Biotechnol 33:1076-1078

Bovy A, De VR, Kemper M, Schijlen E, Almenar PM, Muir S, Collins G, Robinson S, Verhoeyen M, Hughes S (2002) High-flavonol tomatoes resulting from the heterologous expression of the maize transcription factor genes LC and C1. Plant Cell 14:2509-2526

Brooks C, Nekrasov V, Lippman ZB, Van EJ (2014) Efficient gene editing in tomato in the first generation using the clustered regularly interspaced short palindromic repeats/CRISPR-associated9 system. Plant Physiol 166:1292-1297

Broun P, Liu Y, Queen E, Schwarz Y, Abenes ML, Leibman M (2006) Importance of transcription factors in the regulation of plant secondary metabolism and their relevance to the control of terpenoid accumulation. Phytochem Rev 5:27-38

Butelli E, Titta L, Giorgio M, Mock HP, Matros A, Peterek S, Schijlen E, Hall RD, Bovy AG, Luo J (2008) Enrichment of tomato fruit with health-promoting anthocyanins by expression of select transcription factors. Nat Biotechnol 26:1301-1308

Cárdenas PD, Sonawane PD, Pollier J, Vanden Bossche R, Dewangan V, Weithorn E, Tal L, Meir S, Rogachev I, Malitsky S, Giri AP, Goossens A, Burdman S, Aharoni A (2016) GAME9 regulates the biosynthesis of steroidal alkaloids and upstream isoprenoids in the plant mevalonate pathway. Nat Commun 7:1-16

Carrillo L, Herrero I, Cambra I, Sánchez-Monge R, Diaz I, Martinez M (2011) Differential in vitro and in vivo effect of barley cysteine and serine protease inhibitors on phytopathogenic microorganisms. Plant Physiol Biochem 49:1191-1200

Century K, Reuber TL, Ratcliffe OJ (2008) Regulating the regulators: the future prospects for transcription-factor-based agricultural biotechnology products. Plant Physiol 147:20-29

Che P, Zhao ZY, Glassman K, Dolde D, Hu TX, Jones TJ, Obukosia $S$, Wambugu F, Albertsen MC (2016) Elevated vitamin E content improves all-trans $\beta$-carotene accumulation and stability in biofortified sorghum. Proc Natl Acad Sci USA 113:11040-11045

Consortium TG (2012) The tomato genome sequence provides insights into fleshy fruit evolution. Nature 485:635-641

Dan Y, Yan H, Munyikwa T, Dong J, Zhang Y, Armstrong CL (2006) MicroTom - a high-throughput model transformation system for functional genomics. Plant Cell Rep 25:432-441

Eshed Y, Zamir D (1995) An introgression line population of Lycopersicon pennellii in the cultivated tomato enables the identification and fine mapping of yield-associated QTL. Genetics 141:1147-1162

Farré G, Blancquaert D, Capell T, Van DSD, Christou P, Zhu C (2014) Engineering complex metabolic pathways in plants. Annu Rev Plant Biol 65:187-223

Fischer R, Vaquero-Martin C, Sack M, Drossard J, Emans N, Commandeur U (1999) Towards molecular farming in the future: transient protein expression in plants. Biotechnol Appl Biochem 30:113-116

Frary A, Nesbitt TC, Frary A, Grandillo S, Van Der Knaap E, Cong B, Liu J, Meller J, Elber R, Alpert KB, Tanksley SD (2000) fw2. 2: a quantitative trait locus key to the evolution of tomato fruit size. Science 289:85-88

Fridman E, Pleban T, Zamir D (2000) A recombination hotspot delimits a wild-species quantitative trait locus for tomato sugar content to 484 bp within an invertase gene. Proc Natl Acad Sci USA 97:4718-4723

Fu R, Martin C, Zhang Y (2018) Next-generation plant metabolic engineering, inspired by an ancient Chinese irrigation system. Mol Plant 11:47-57

Georgiev V, Ilieva M, Bley T, Pavlov A (2008) Betalain production in plant in vitro systems. Acta Physiol Plant 30:581-593

Gonzali S, Mazzucato A, Perata P (2009) Purple as a tomato: towards high anthocyanin tomatoes. Trends Plant Sci 14:237-241

Hannon GJ (2002) RNA interference. Nature 418:244-251

Itkin M, Heinig U, Tzfadia O, Bhide AJ, Shinde B, Cardenas PD, Bocobza SE, Unger T, Malitsky S, Finkers R (2013) Biosynthesis of antinutritional alkaloids in solanaceous crops is mediated by clustered genes. Science 341:175-179

Kunzler A, Kolling EA, da Silva-Jr JD, Gasparotto J, de Bittencourt Pasquali MA, Moreira JC, Gelain DP (2017) Retinol (vitamin A) increases $\alpha$-synuclein, $\beta$-amyloid peptide, tau phosphorylation and RAGE content in human SH-SY5Y neuronal cell line. Neurochem Res 42:2788-2797

Kushibiki T, Tabata Y (2005) Preparation of poly(ethylene glycol)introduced cationized gelatin as a non-viral gene carrier. J Biomater Sci Polym Ed 16:1447-1461

Lin T, Zhu G, Zhang J, Xu X, Yu Q, Zheng Z, Zhang Z, Lun Y, Li S, Wang $X$ (2014) Genomic analyses provide insights into the history of tomato breeding. Nat Genet 46:1220-1226

Liu X, Ding W, Jiang H (2017a) Engineering microbial cell factories for the production of plant natural products: from design principles to industrial-scale production. Microb Cell Fact 16:125-134

Liu Y, Zhong Y, Chen H, Wang D, Wang M, Ou JS, Xia M (2017b) Retinol binding protein-dependent cholesterol uptake regulates macrophage foam cell formation and promotes atherosclerosis. Circulation 135:1339-1354

Lu Y, Rijzaani H, Karcher D, Ruf S, Bock R (2013) Efficient metabolic pathway engineering in transgenic tobacco and tomato plastids with synthetic multigene operons. Proc Natl Acad Sci USA 110:623-632

Luo J (2015) Metabolite-based genome-wide association studies in plants. Curr Opin Plant Biol 24:31-38

Luo J, Butelli E, Hill L, Parr A, Niggeweg R, Bailey P, Weisshaar B, Martin C (2008) AtMYB12 regulates caffeoyl quinic acid and flavonol synthesis in tomato: expression in fruit results in very high levels of both types of polyphenol. Plant J 56:316-326

Maeo K, Tokuda T, Ayame A, Mitsui N, Kawai T, Tsukagoshi H, Ishiguro S, Nakamura K (2009) An AP2-type transcription factor, WRINKLED1, of Arabidopsis thaliana binds to the AW-box sequence conserved among proximal upstream regions of genes involved in fatty acid synthesis. Plant J Cell Mol Biol 60:476-487

Marchive C, Nikovics K, To A, Lepiniec L, Baud S (2015) Transcriptional regulation of fatty acid production in higher plants: molecular bases and biotechnological outcomes. Eur J Lipid Sci Technol 116:1332-1343

Martin C (1996) Transcription factors and the manipulation of plant traits. Curr Opin Biotechnol 7:130-138

Martin C, Li J (2017) Medicine is not health care, food is health care: plant metabolic engineering, diet and human health. New Phytol 216:699-719

Mène-Saffrané L, Pellaud S (2017) Current strategies for vitamin E biofortification of crops. Curr Opin Biotechnol 44:189-197

Muir SR, Collins GJ, Robinson S, Hughes S, Bovy A, De Vos CR, van Tunen AJ, Verhoeyen ME (2001) Overexpression of petunia 
chalcone isomerase in tomato results in fruit containing increased levels of flavonols. Nat Biotechnol 19:470-474

Nogueira M, Enfissi E, Martínez MV, Menard GN, Driller RL, Eastmond PJ, Schuch W, Sandmann G, Fraser PD (2017) Engineering of tomato for the sustainable production of ketocarotenoids and its evaluation in aquaculture feed. Proc Natl Acad Sci USA 114:10876-10881

O’Neill EC, Kelly S (2016) Engineering biosynthesis of high-value compounds in photosynthetic organisms. Crit Rev Biotechnol 37:779-802

Olmedilla B, Granado F, Blanco I, Vaquero M (2003) Lutein, but not alpha-tocopherol, supplementation improves visual function in patients with age-related cataracts: a 2 -y double-blind, placebocontrolled pilot study. Nutrition 19:21-24

Orzaez D, Medina A, Torrez S, Fernandez-Moreno JP, Rambla JL, Fernandez-Del-Carmen A, Butelli E, Martin C, Granell A (2009) A visual reporter system for virus-induced gene silencing in tomato fruit based on anthocyanin accumulation. Plant Physiol 150:1122-1134

Pan C, Ye L, Qin L, Liu X, He Y, Wang J, Chen L, Lu G (2016) CRISPR/Cas9-mediated efficient and heritable targeted mutagenesis in tomato plants in the first and later generations. Sci Rep 6:24765

Peixoto JV, Neto CM, Campos LF, Dourado WS, Nogueira AP, Nascimento AD (2017) Industrial tomato lines: morphological properties and productivity. Genet Mol Res 16:1-15

Polturak G, Grossman N, Vela-Corcia D, Dong Y, Nudel A, Pliner M, Levy M, Rogachev I, Aharoni A (2017) Engineered gray mold resistance, antioxidant capacity, and pigmentation in betalainproducing crops and ornamentals. Proc Natl Acad Sci USA 114:9062-9067

Potrykus I (1991) Gene transfer to plants assessment of published approaches and results. Annu Rev Plant Physiol Plant Mol Biol 42:205-225

Powell ALT, Nguyen CV, Hill T, Cheng KL, Figueroa-Balderas R, Aktas H, Ashrafi H, Pons C, Fernández-Muñoz R, Vicente A, Lopez-Baltazar J, Barry CS, Liu Y, Chetelat R, Granell A, Deynze AV, Giovannoni JJ, Bennett AB (2012) Uniform ripening encodes a golden 2-like transcription factor regulating tomato fruit chloroplast development. Science 336:1711-1715

Rodríguez-Leal D, Lemmon ZH, Man J, Bartlett ME, B.Lippman Z (2017) Engineering quantitative trait variation for crop improvement by genome editing. Cell 171:1-11

Ru M, Wang K, Bai Z, Peng L, He S, Pei T, Jia Y, Li H, Liang Z (2016) Molecular cloning and characterisation of two enzymes involved in the rosmarinic acid biosynthesis pathway of Prunella vulgaris L. Plant Cell Tissue Organ Culture 128:381-390

Sato S, Frederiksen R, Cornwall MC, Kefalov VJ (2017) The retina visual cycle is driven by cis retinol oxidation in the outer segments of cones. Vis Neurosci 34:1-8

Scarano A, Butelli E, De Santis S, Cavalcanti E, Hill L, De Angelis M, Giovinazzo G, Chieppa M, Martin C, Santino A (2017) Combined dietary anthocyanins, flavonols and stilbenoids alleviate inflammatory bowel disease symptoms in mice. Front Nutr 4:75

Schijlen E, Ch RDV, Jonker H, Van Den Broeck H, Molthoff J, Van TA, Martens S, Bovy A (2006) Pathway engineering for healthy phytochemicals leading to the production of novel flavonoids in tomato fruit. Plant Biotechnol J 4:433-444

Schwinn KE (2016) The dope on 1-DOPA formation for betalain pigments. New Phytol 210:269-283

Siddiqui MW, Ayalazavala JF, Dhua RS (2015) Genotypic variation in tomatoes affecting processing and antioxidant attributes. Crit Rev Food Sci Nutr 55:1819-1835

Sonawane PD, Pollier J, Panda S, Szymanski J, Massalha H, Yona M, Unger T, Malitsky S, Arendt P, Pauwels L (2016) Plant cholesterol biosynthetic pathway overlaps with phytosterol metabolism. Nat Plants 3:16205-16218

Soyk S, Lemmon ZH, Oved M, Fisher J, Liberatore KL, Park SJ, Goren A, Jiang K, Ramos A Van dKE (2017) Bypassing negative epistasis on yield in tomato imposed by a domestication gene. Cell 169:1142-1155

Sprink T, Metje J, Hartung F (2015) Plant genome editing by novel tools: TALEN and other sequence specific nucleases. Curr Opin Biotechnol 32:47-53

Suresh BV, Roy R, Sahu K, Misra G, Chattopadhyay D (2014) Tomato genomic resources database: an integrated repository of useful tomato genomic information for basic and applied research. PLoS One 9:e86387

Tieman D, Zhu G, Resende M Jr, Lin T, Nguyen C, Bies D, Rambla JL, Beltran KS, Taylor M, Zhang B (2017) A chemical genetic roadmap to improved tomato flavor. Science 355:391-394

Tzin V, Rogachev I, Meir S, Moyal Ben Zvi M, Masci T, Vainstein A, Aharoni A, Galili G (2013) Tomato fruits expressing a bacterial feedback-insensitive 3-deoxy-d-arabino-heptulosonate 7-phosphate synthase of the shikimate pathway possess enhanced levels of multiple specialized metabolites and upgraded aroma. J Exp Bot 64:4441-4452

USDA (2017) National Agricultural Statistics Service - Vegetables 2016 Summary

Van EH, Kelly AA, Menard G, Eastmond PJ (2014) Multigene engineering of triacylglycerol metabolism boosts seed oil content in Arabidopsis. Plant Physiol 165:30-36

Vanhercke T, El TA, Liu Q, Zhou XR, Shrestha P, Divi UK, Ral JP, Mansour MP, Nichols PD, James CN (2014) Metabolic engineering of biomass for high energy density: oilseed-like triacylglycerol yields from plant leaves. Plant Biotechnol J 12:231-239

Vogt T (2010) Phenylpropanoid biosynthesis. Mol Plant 3:2-20 (Oxford University Press/USA)

Wang D, Seymour G (2017) Tomato flavor: lost and found? Mol Plant 10:782-784

Yin LH, Xu LN, Wang XN, Lu BN, Liu YT, Peng JY (2010) An economical method for isolation of dioscin from Dioscorea nipponica Makino by HSCCC coupled with ELSD, and a computer-aided UNIFAC mathematical model. Chromatographia 71:15-23

Zamir D (1995) An introgression line population of Lycopersicon pennellii in the cultivated tomato enables the identification and fine mapping of yield-associated. QTL Genet 141:1147-1162

Zamir D (2001) Improving plant breeding with exotic genetic libraries. Nat Rev Genet 2:983-989

Zhang Y, Butelli E, Alseekh S, Tohge T, Rallapalli G, Luo J, Kawar PG, Hill L, Santino A, Fernie AR, Martin C (2015) Multi-level engineering facilitates the production of phenylpropanoid compounds in tomato. Nat Commun 6:8635-8655

Zhang PC, Wu CR, Wang ZL, Wang LY, Han Y, Sun SL, Li QS, Ma L (2017) Effect of lutein supplementation on visual function in nonproliferative diabetic retinopathy. Asia Pac J Clin Nutr 26:406-411

Zhu CF, Bai C, Sanahuja G, Yuan DW, Farré G, Naqvi S, Shi LX, Capell T, Christou P, Landrum JT (2010) The regulation of carotenoid pigmentation in flowers. Arch Biochem Biophys 504:132-141

Zhu G, Wang S, Huang Z, Zhang S, Liao Q, Zhang C, Lin T, Qin M, Peng M, Yang C, Cao X (2018) Rewiring of the fruit metabolome in tomato breeding. Cell 172:249-261

Zsögön A, Cermak T, Dan V, Peres LEP (2017) Genome editing as a tool to achieve the crop ideotype and de novo domestication of wild relatives: case study in tomato. Plant Sci Int J Exp Plant Biol 256:120-130 